\title{
Student Learning in Higher Education: a Commentary
}

\author{
John T. E. Richardson ${ }^{1}$
}

Published online: 7 April 2017

(C) Springer Science+Business Media New York 2017

\begin{abstract}
This commentary begins by summarizing the five contributions to this special issue and briefly recapping the background to the topic of student learning in higher education. Narrative and systematic reviews are compared, and the relative value of different bibliographic databases in the context of systematic reviews is assessed. The importance of measures of effect size is stressed. The relationship of the five contributions to early research on levels of processing and approaches to learning is discussed, along with the presage-process-product model of student learning and historical discussions that are relevant to the current theoretical discussions. This field has benefited from the development of more robust instrumentation, but researchers must continue to develop new kinds of measure, including online measures of students' strategy use. Researchers need to consider ways of enhancing the quality of student learning through the use of problem-based curricula and other student-centered approaches. Finally, it is suggested that researchers into student learning need to evaluate whether their concepts, methods, theories, and findings are valid in online environments and to investigate how curricula in higher education can build upon those in secondary education.
\end{abstract}

Keywords Approaches to learning · Effect size · Higher education · Levels of processing · Problem-based learning $\cdot$ Systematic reviews

\section{Background}

In different ways, all of the contributors have reflected on what has been achieved since the publication of the previous special issue on student learning in higher education (Olkinuora and Lonka 2004). One obvious difference is that the previous special issue was concerned mainly with conceptual and methodological issues, whereas this special issue has been more concerned with substantive theoretical issues. The previous special issue did make it clear that the field was divided between two different traditions: a North American tradition focusing on self-regulation in learning (SRL) and a European/Australian tradition focusing on student

John T. E. Richardson

john.t.e.richardson@open.ac.uk

1 Institute of Educational Technology, The Open University, Milton Keynes MK7 6AA, UK 
approaches to learning (SAL). That division is still very apparent in the current special issue, with Dinsmore and Zusho representing the former tradition and Asikainen and Gijbels, Fryer, and Vermunt and Donche representing the latter tradition.

Having different traditions in a field of research is not necessarily a bad thing. However, Pintrich (2004) observed that there were philosophical and methodological differences between the two perspectives, and he talked rather melodramatically of them being separated by a chasm. He went so far as to claim that models based upon the two perspectives were incommensurable. However, Richardson (2007a) showed that measures of SRL could be accommodated within the same model as measures of SAL. Using a large sample of distance-learning students, he demonstrated that there was a close relationship between their motives and strategies, on the one hand, and their approaches to learning, on the other hand. Based on path analysis, Richardson concluded that the causal link between variations in motives and attitudes and variations in study behavior was bidirectional. In particular, higher scores on various aspects of a strategic approach to learning seemed to give rise to higher scores on intrinsic goal orientation and self-efficacy for learning but lower scores on test anxiety; conversely, however, higher scores on self-efficacy for learning seemed to give rise to higher scores on relating ideas but lower scores on fear of failure.

\section{Narrative Versus Systematic Review}

In fact, there is another divide apparent in the five contributions to this special issue. The articles by Fryer and Zusho adopted the traditional techniques of narrative review, which leave the reviewer free to construct his or her own story about the chosen topic. In contrast, the articles by Asikainen and Gijbels, by Dinsmore, and by Vermunt and Donche adopted the techniques of systematic review, based on a more deliberate and structured mining of the literature. Nowadays, there are more-or-less agreed standards for conducting and reporting the findings of a systematic review, which make it easier to appreciate the strengths and limitations of the exercise.

In his systematic review of research into strategic processing, Dinsmore (this issue) chose to confine himself to articles published between 2011 and 2016 that had been included in the PsycINFO database. He justified this on the basis that the database covered all the high-impact journals in psychology. Of course, PsycINFO does not actually contain the articles themselves, merely their titles, abstracts, keywords, and metadata, and this leaves open the possibility that some relevant publications might have been missed. A possible remedy would be to use more traditional forward and backward searching of the relevant literature based upon cross-citations (Vermunt and Donche, this issue). Another point is that relevant work might have been contained in journals that are not covered by PsycINFO at all, most obviously in educational journals.

In their systematic review of research into learning patterns, Vermunt and Donche (this issue) chose instead to use the bibliographic database of the Educational Resources Information Center (ERIC) as well as Web of Science. In contrast to Dinsmore's concern with highimpact journals, it might be noted that, in the past, researchers could deposit their own material in the ERIC collection, and so a significant proportion of the records relate to "gray" literature that has not been peer-reviewed. The collection also contains postgraduate dissertations and conference presentations, which will have been peer-reviewed to a greater or lesser extent. (With effect from January 2016, ERIC introduced a selection policy that limited new records to material that has undergone some kind of review process, but this policy has not been applied retrospectively.) 
Asikainen and Gijbels (this issue) used all three databases (ERIC, PsycINFO, and Web of Science) in their systematic review of longitudinal research on approaches to learning. There are, however, other databases that they might have used. Google Scholar does not disclose how many documents it contains, but it is thought to be several times as many as Web of Science. For instance, Richardson (2015a) examined the citations of the article by Marton and Säljö (1976), which is mentioned in several of the contributions to this special issue. Richardson found that it had been cited in 957 publications listed in Web of Science but in 3764 publications listed in Google Scholar. So, even though they used three different databases, perhaps Asikainen and Gijbels should have cast their net yet more widely.

Of course, systematic reviews can only cover research which has actually been published. Dinsmore (this issue) suggested that there was a potential bias in such reviews; in that, published studies may be more likely to exhibit statistically significant effects than are unpublished studies. In fact, there is a more insidious problem, which is that of reporting bias. Researchers may well assume that journal editors and reviewers will exhibit a publication bias, and so they anticipate this by reporting only those effects that are statistically significant (Dawson and Dawson 2017). However, whether there is publication bias or reporting bias in any particular research domain is an empirical matter. It should not be taken for granted but should be investigated on a case-by-case basis. Indeed, there are examples where there is little or no evidence for any publication bias in the published literature. One such example is the literature on gender differences in cognitive abilities [see Richardson (1997) for a detailed discussion of this literature].

\section{Measures of Effect Size}

Asikainen and Gijbels (this issue) focused their attention upon whether or not particular studies found statistically significant changes in students' approaches to learning over the course of time. One limitation of their systematic review is that they failed to report the magnitude of these effects. Nowadays, it is commonly recognized that differences, changes, or associations that are of little theoretical or practical importance may achieve statistical significance simply because the researchers have used large samples of participants. In fact, many journals require authors to report measures of effect size, and even when they fail to do so, readers can usually calculate such measures for themselves from the inferential statistics that have been reported.

Cohen (1969) described several different measures of effect size, and for each measure, he put forward suggested benchmarks for "small," "medium," and "large" effects. His suggestions have become widely accepted in the interim. By way of illustration, Richardson (2013) carried out a cross-sectional study to investigate variations in students' approaches to learning across the adult life span using data from 3861 distance-learning students. He found age differences in the students' use of a deep approach, a strategic approach, and a surface approach that all achieved a high level of statistical significance. Nevertheless, on Cohen's benchmarks, these variations only constituted small effects of little or no theoretical or practical importance. In other words, age is not an important determinant of individual differences in approaches to learning.

To return to the contribution by Asikainen and Gijbels, where researchers have reported statistically significant changes in students' approaches to learning using longitudinal designs, it would be interesting to know whether these constituted small, medium, or large effects based on Cohen's criteria. It would also be interesting to know whether effects of similar magnitude have been found using cross-sectional designs. One reason for expecting cross-sectional 
research to yield somewhat different findings is that longitudinal studies tend to be bedeviled by the problem of subject attrition, as Asikainen and Gijbels (this issue) mentioned. However, the situation is more complex than they acknowledged.

The study by Watkins and Hattie (1985) which they cited provides detailed evidence on this. Watkins and Hattie surveyed Australian tertiary students in their first year of study and then tried to follow them up in their third year of study. Many students had continued in their studies and contributed to the follow-up survey. Other students had dropped out of tertiary education and were not available to be surveyed. Yet others had continued in their studies but declined to participate in the follow-up survey. When Watkins and Hattie examined the questionnaire scores obtained by the students in the first survey, there were systematic and significant differences among these three groups. Such differences need to be explored more thoroughly in future research, since they might help us to understand why some students drop out of higher education when others do not and why some students participate in surveys when others do not.

Returning to the topic of effect size, it should be noted that Dinsmore (this issue) did attempt to evaluate the size of the effects that had been obtained in previous research on strategic processing. However, he seems to have used rather arbitrary cutoffs to determine large and small effects that are not sanctioned by current or recent research practice. It might have been more useful to use the benchmarks put forward by Cohen (1969), which have stood the test of time and are nowadays widely cited in educational and psychological research.

\section{Levels of Processing and Approaches to Learning}

Dinsmore began his story with the accounts of levels of processing that were put forward by Craik and Lockhart (1972) and by Marton and Säljö (1976). The former was firmly within the domain of cognitive psychology, although it did evolve in subsequent decades (see Craik 2002). Dinsmore suggested that Marton and Säljö took a more constructivist approach. That is not quite correct. In his original writings, Marton (1975) adopted a perfectly literal account of Craik and Lockhart's position. It was only later, in the 1980s, that he encouraged a different interpretation based on the research that he and his colleagues had been doing on approaches to studying and conceptions of learning [see Richardson (2015a) for further discussion].

In Dinsmore's story, Craik and Lockhart begat Marton and Säljö, and Marton and Säljö begat Biggs (1978). Dinsmore suggested that, for Biggs, students' levels of processing were relatively stable, but this ignores a European tradition which holds that students' approaches to learning depend primarily on the context of learning. This is implicit in the work of Marton and his students, but it became explicit in Laurillard's (1979) research and was highlighted in the writings of Ramsden (1979) and Gibbs (1981). Nowadays, many people take it for granted that students' approaches to learning are contingent and are intimately related to their perceptions of their teaching-learning environment (see Asikainen and Gijbels, this issue). Dinsmore added that, while it is often assumed that deep-level strategies will lead to better performance, this does not always appear to be the case. In fact, it has been known for a long time that whether deep-level processing leads to improved retention depends on how that retention is measured. For instance, deep-level processing appears to lead to improved retention in explicit memory tasks but not in implicit memory tasks (e.g., Roediger et al. 1992).

As Fryer (this issue) explained, Biggs (1985) proposed that there were three kinds of variables involved in student learning: "presage" variables, consisting of characteristics of the students and of their institutional context; "process" variables, consisting of their motives and 
their strategies for learning; and "product" variables, consisting of performance outcomes. This is generally known as the presage-process-product or " $3 \mathrm{P}$ " model. Many people have found it helpful, but it needs to be elaborated in certain respects.

First, Biggs (1993b) himself pointed out that the expression "approach to learning" had come to have two different meanings: "the processes adopted prior to, which directly determine, the outcome of learning" and "predispositions to adopt particular processes" (p. 6; italics in original). In research practice, the process component of the $3 \mathrm{P}$ model is usually measured using such instruments as the Study Process Questionnaire (of which more in a moment), but these are clearly measuring the predisposition to go about studying in a certain way, not the actual processes involved in specific learning tasks. Consequently, Richardson (2000, pp. 74 79) argued that the $3 \mathrm{P}$ model needed to be elaborated into a series of four different stages: presage, predisposition, process, and product. Indeed, a model with precisely this structure had been put forward by Newble and Entwistle (1986).

As Fryer (this issue) also mentioned, the 3P model was a classic linear theory, in that presage variables influenced process variables and both influenced product variables. However, Biggs (1991) incorporated feedback loops whereby students' observations of their own learning outcomes could lead them to modify their beliefs about their own capabilities and could also influence teachers and institutions to modify their instructional practices. Eventually, Biggs (1993a) adopted a systems approach which allowed for the possibility of interactions among all of the different components of the system. This is also a feature of the model of learning patterns put forward by Vermunt and Donche (this issue). It clearly introduces a much greater degree of flexibility, but it also seems to render these models unfalsifiable, because they can accommodate virtually any pattern of empirical results that might be obtained.

Moreover, on closer examination, the detailed assumptions of the model do not appear to be plausible. For instance, the model assumes that personal characteristics influence the learning process, a position endorsed by Zusho (this issue). This is plausible for some characteristics such as age, gender, and personality, but not all. Zusho specifically mentions a student's ethnicity. It is well known that ethnicity is related to academic attainment in higher education (see Richardson 2015b), but it is not at all clear how it might be involved in learning. Rather, it is more likely to be a proxy for other characteristics that influence both learning and attainment. The notion that this link is bidirectional in nature is also implausible. As Vermunt and Donche themselves remarked, at least some personal factors such as a student's age (to which one might add their gender and ethnicity) will not change as a result of their learning. It might also be noted that Biggs does not seem to have pursued the notion of a systems approach since his 1993 paper.

Finally, it is important to remember that Biggs' (1985) account was itself based upon the presage-process-product model of classroom teaching that had been put forward by Dunkin and Biddle (1974, pp. 36-48). In this model, characteristics of the teachers were regarded as presage variables, whereas the characteristics of the students became part of the institutional context that influenced the nature of their teaching. Price (2014) emphasized that a complete account of teaching and learning in higher education needs to integrate both these models. Such an account clearly reflects the complexity of the teaching-learning relationship and why it is so difficult to improve the quality of either teaching or learning in higher education.

Craik and Lockhart's (1972) levels-of-processing framework has been mentioned, but there are other historical accounts that might be relevant today. For instance, at a number of points, Dinsmore (this issue) referred to research on the acquisition of expertise. It would be interesting to relate his ideas to those of Anderson (1976), who devised a detailed model of the acquisition of skills of various kinds in the 1970s and 1980s. Dinsmore suggested that 
learners might move from a surface approach to a deep approach as they become more expert. However, in his theory of the Adaptive Control of Thought, Anderson went further and argued that learners' knowledge was "compiled" (rather as a computer program is compiled into machine language) so that it became procedural rather than declarative in nature.

Dinsmore also presented an integrative model that illustrated how strategic processing depends upon aspects of the person, the task, and the broader learning environment. He seems to be saying that aspects of the person are relatively stable, that aspects of the task are malleable, and that aspects of the environment are most amenable to change. This is strongly reminiscent of Curry's (1983) "onion" model of learning styles, in which the deeper layers of the onion are less influenced by the context and hence more permanent. On this model, measures of instructional preference are amenable to change, measures of information processing style are more persistent, and measures of cognitive personality style are relatively permanent. There is at least an apparent isomorphism between Dinsmore's account of strategic processing and Curry's model of learning styles that would be worth investigating in future research.

\section{Instrumentation}

Asikainen and Gijbels (this issue) were evidently disappointed that their review of prior research failed to demonstrate any consistent changes in students' approaches to learning over a program of study. One possible explanation for such inconsistencies is inadequate research instrumentation. Asikainen and Gijbels mentioned that the instrument most commonly used in the studies that they reviewed was Biggs' (1985) Study Process Questionnaire. Richardson (2000, pp. 69-85) evaluated the research evidence that had been obtained using this questionnaire and concluded that it could not be recommended for use in future investigations. In fact, most of the original instrumentation used to monitor students' approaches to learning was probably not sufficiently robust to address wider theoretical and practical issues.

To take another example, as has already been mentioned, it is often assumed that there is a close relationship between students' perceptions or experiences in a particular environment and the approaches to learning that they adopt in that environment. Nevertheless, until the end of the last century, the evidence for this assumption was strikingly weak. It was only when researchers started to use newer and more robust instruments to monitor students' perceptions and their approaches to learning that the picture became clearer and we could at last be reassured that there was an intimate relationship between the two kinds of construct (see Richardson 2007b).

The fact that we do now seem to have more robust questionnaires for monitoring student learning should not discourage researchers from seeking new kinds of measure. For instance, Zusho (this issue) noted that there had been an increasing interest in "online" measures of SRL, prompted in part by a concern that responses to questionnaires and other "offline" measures will be biased by the learners' implicit theories and reconstructions. Richardson (2015a) made a very similar point in the context of research concerned with levels of processing and approaches to learning. As Dinsmore (this issue) acknowledged, students' retrospective reports of how they have just carried out specific learning tasks will be highly informative about their strategy use. Ericsson and Simon (1993, pp. 17-32) concluded that such reports would yield accurate empirical findings precisely because they are likely to be based on representations in recent memory. However, students' responses to questionnaires about how they normally go about studying are likely to be based on "inferences and reconstructions derived from their own subjective and implicit theories of the processes involved" (Richardson 2015a, p. 263). 
The development of online measures of both SRL and SAL might address one of the concerns raised by Vermunt and Donche (this issue). They referred to a number of ways in which the learning pattern model could be moved forward. One would be to be more precise about the kinds of cognitive strategies that different students use. The rapidly expanding field of learning analytics provides both researchers and practitioners with the opportunity to monitor students' strategic decisions in online environments in minute detail and in real time. Linking this technology to the collection of students' retrospective reports regarding how they have just carried out specific learning tasks could be the basis of a fruitful cross-fertilization between the learning pattern approach and Dinsmore's account of strategic processing.

\section{Interventions}

As previously noted, Asikainen and Gijbels (this issue) found no clear evidence for any systematic changes in students' approaches to learning during the course of their studies. This might be due to inadequate instrumentation, but, if it is genuine, it is potentially important. It implies that enhancing students' approaches to learning has to be brought about through specific interventions rather than through some process of natural development. One intervention that is mentioned by Asikainen and Gijbels is the introduction of a problem-based curriculum rather than a traditional, subject-based curriculum. Zusho (this issue) painted a rather negative picture of problem-based learning and other student-centered approaches, implying that there is a lack of alignment between student-centered learning environments and deep approaches to learning. In fact, the situation is a good deal more positive than this.

Investigations carried out during the 1980s using both longitudinal and cross-sectional research designs found that problem-based curricula enhanced the use of a deep approach and discouraged the use of a surface approach in comparison with subject-based curricula (Coles 1985; Newble and Clarke 1986). More recent investigations have generally confirmed this result (Hall et al. 2004; Kieser et al. 2005; Richardson et al. 2007; Sadlo and Richardson 2003). Students who have followed problem-based curricula may also show higher attainment than those who have followed subject-based curricula (Polanco et al. 2004). In general, those students who have followed problem-based curricula display superior long-term retention, skill development, and satisfaction with their programs (Strobel and van Barneveld 2009).

There are however some complications. One is that some programs may only introduce problem-based curricula in a half-hearted or "hybrid" manner (see Sadlo and Richardson 2003). Another is that students may make sense of problem-based curricula in different ways. Prosser and Sze (2014) found that some medical students thought that problem-based learning was concerned with learning how to solve problems individually; these students de-contextualized the problems that they were given and did not appreciate their clinical relevance. Other medical students were aware of the importance of solving problems in groups and related the problems that they were given to their clinical context. The former students tended to adopt a surface approach to studying, whereas the latter were more likely to adopt a deep approach.

\section{Lines for Future Investigation}

I would like to conclude by suggesting two lines for future investigation that do not seem to have been mentioned in the various contributions to this special issue. First, Vermunt and Donche (this issue) mentioned the wide range of new learning opportunities that had been made available through the use of online resources. It would be particularly interesting to look 
at how these opportunities affect and are affected by external regulation. In fact, researchers generally need to explore whether the concepts, methods, theories, and findings that have emerged from our investigations of face-to-face higher education remain valid in online environments. To date, these environments have been seriously under-researched.

The second area is the relationship between curricula in higher education and those in secondary education. In some subjects (such as mathematics), it is clear that the curriculum in higher education simply builds upon what has been taught in secondary education in a moreor-less cumulative manner. However, in some other subjects, the curriculum in higher education is effectively being taught ab initio, and there is little if anything to build upon from the secondary curriculum. The idea that a deep approach to learning somehow gradually emerges in higher education is more plausible in the latter case than in the former. In fact, researchers in higher education might need to be more modest in their claims and to acknowledge that the phenomena in which they are interested might well be manifest earlier in the life span. For instance, when a teenager reads a Harry Potter novel, they are unlikely to be seeking to memorize the content for the purposes of some improbable future examination. On the contrary, they are likely to be using a full-blown deep approach precisely as it has been defined by researchers into higher education.

Acknowledgements I am grateful to the editors of this special issue for inviting me to comment on the various contributions and to the contributors for providing us with some interesting articles and plenty of food for thought.

The Contributions The special issue contained a total of five contributions. They can be briefly summarized as follows:

- Asikainen and Gijbels described a systematic review of the research literature on whether there are changes in students' approaches to learning during their studies. They identified 43 studies containing relevant longitudinal results but concluded that there was no clear evidence for systematic changes in students' approaches to learning. - Dinsmore provided a framework to understand the notion of strategic processing by examining the conceptual and methodological characteristics of studies published between 2011 and 2016. He arrived at three conclusions: first, we actually do not know very much about the development of strategic processing; second, quality and conditional use explain performance more than simple strategy use; and third, person and environmental factors influence the effectiveness of different strategies.

- Vermunt and Donche provided a systematic review of research into the learning pattern model over the last decade or so. The model had previously existed for nearly 20 years, but it had few supporters during that period. Since the turn of the century, it has become clear that the learning pattern model offers a distinctive and highly promising framework for studying individual differences in student learning.

- Zusho provided a useful review and update of three different areas of research: research on self-regulated learning, research on patterns of learning, and research on student engagement. Zusho also updated the model proposed by Pintrich and Zusho (2007) to incorporate the most important conclusions from these three areas of research.

- Fryer presented a critique of Biggs' (1985) 3P model of student learning, with the suggestion that the notion of perceived control could serve as an organizing principle that would help to identify new hypotheses using a system approach.

\section{Compliance with Ethical Standards}

Conflict of Interest The authors declare that there is no conflict of interest.

Funding This research did not receive any specific grant from funding agencies in the public, commercial, or not-for-profit sectors. 


\section{References}

Anderson, J. R. (1976). Language, memory, and thought. Mahwah, NJ: Erlbaum.

Biggs, J. B. (1978). Individual and group differences in study processes. British Journal of Educational Psychology, 17, 266-279. doi:10.1111/j.2044-8279.1978.tb03013.x.

Biggs, J. B. (1985). The role of metalearning in study processes. British Journal of Educational Psychology, 55, 185-212. doi:10.1111/j.2044-8279.1985.tb02625.x.

Biggs, J. B. (1991). Approaches to learning in secondary and tertiary students in Hong Kong: some comparative studies. Educational Research Journal, 6, 27-39 Retrieved from http://hkier.fed.cuhk.edu.hk/journal/wpcontent/uploads/2010/06/erj_v6_27-39.pdf.

Biggs, J. B. (1993a). From theory to practice: a cognitive systems approach. Higher Education Research and Development, 12, 73-85. doi:10.1080/0729436930120107.

Biggs, J. (1993b). What do inventories of students' learning processes really measure? A theoretical review and clarification. British Journal of Educational Psychology, 63, 3-19. doi:10.1111/j.2044-8279.1993.tb01038.x.

Cohen, J. (1969). Statistical power analysis for the behavioral sciences. New York, NY: Academic Press.

Coles, C. R. (1985). Differences between conventional and problem-based curricula in their students' approaches to studying. Medical Education, 19, 308-309. doi:10.1111/j.1365-2923.1985.tb01327.x.

Craik, F. I. M. (2002). Levels of processing: past, present... and future? Memory, 10, 305-318. doi:10.1080 $/ 09658210244000135$.

Craik, F. I. M., \& Lockhart, R. S. (1972). Levels of processing: a framework for memory research. Journal of Verbal Learning and Verbal Behavior, 11, 671-684. doi:10.1016/S0022-5371(72)80001-X.

Curry, L. (1983). An organization of learning styles theory and constructs. Paper presented at the Annual Meeting of the American Educational Research Association. Retrieved from ERIC database. (ED235185)

Dawson, P., \& Dawson, S. L. (2017). Sharing successes and hiding failures: "reporting bias" in learning and teaching research. Studies in Higher Education. doi:10.1080/03075079.2016.1258052.

Dunkin, M. J., \& Biddle, B. J. (1974). The study of teaching. New York, NY: Holt, Rinehart, \& Winston.

Ericsson, K. A., \& Simon, H. A. (1993). Protocol analysis: verbal reports as data (rev. ed.). Cambridge, MA: MIT Press.

Gibbs, G. (1981). Teaching students to learn: a student-centred approach. Milton Keynes: Open University Press.

Hall, M., Ramsay, A., \& Raven, J. (2004). Changing the learning environment to promote deep learning approaches in first-year accounting students. Accounting Education, 13, 489-505. doi:10.1080 $/ 0963928042000306837$.

Kieser, J., Herbison, P., \& Harland, T. (2005). The influence of context on students' approaches to learning: a case study. European Journal of Dental Education, 9, 150-156. doi:10.1111/j.1600-0579.2005.00383.x.

Laurillard, D. (1979). The processes of student learning. Higher Education, 8, 395-409. doi:10.1007 /BF01680527.

Marton, F. (1975). On non-verbatim learning: I. Level of processing and level of outcome. Scandinavian Journal of Psychology, 16, 273-279. doi:10.1111/j.1467-9450.1975.tb00193.x.

Marton, F., \& Säljö, R. (1976). On qualitative differences in learning: I. Outcome and process. British Journal of Educational Psychology, 46, 4-11. doi:10.1111/j.2044-8279.1976.tb02980.x.

Newble, D. J., \& Clarke, R. M. (1986). The approaches to learning of students in a traditional and in an innovative problem-based medical school. Medical Education, 20, 267-273. doi:10.1111/j.1365-2923.1986. tb01365.x.

Newble, D. J., \& Entwistle, N. J. (1986). Learning styles and approaches: implications for medical education. Medical Education, 20, 162-175. doi:10.1111/j.1365-2923.1986.tb01163.x.

Olkinuora, E., \& Lonka, K. (2004). Measuring studying and learning in higher education: conceptual and methodological issues [special issue]. Educational Psychology Review, 16(4).

Pintrich, P. R. (2004). A conceptual framework for assessing motivation and self-regulated learning in college students. Educational Psychology Review, 16, 385-407. doi:10.1007/s10648-007-9050-7.

Pintrich, P. R., \& Zusho, A. (2007). Motivation and self-regulated learning in the college classroom. In R. Perry \& J. Smart (Eds.), Handbook on teaching and learning in higher education (pp. 731-810). Dordrecht: Springer.

Polanco, R., Calderón, P., \& Delgado, F. (2004). Effects of a problem-based learning program on engineering students' academic achievements in a Mexican university. Innovations in Education and Teaching International, 41, 145-155. doi:10.1080/1470329042000208675.

Price, L. (2014). Modelling factors for predicting student learning outcomes in higher education. In D. Gijbels, V. Donche, J. T. E. Richardson, \& J. D. Vermunt (Eds.), Learning patterns in higher education: Dimensions and research perspectives (pp. 56-77). London: Routledge. 
Prosser, M., \& Sze, D. (2014). Problem-based learning: student learning experiences and outcomes. Clinical Linguistics and Phonetics, 28, 112-123. doi:10.3109/02699206.2013.820351.

Ramsden, P. (1979). Student learning and perceptions of the academic environment. Higher Education, 8, 411427. doi:10.1007/BF01680529.

Richardson, J. T. E. (1997). Conclusions from the study of gender differences in cognition. In P. J. Caplan, M. Crawford, J. S. Hyde, \& J. T. E. Richardson, Gender differences in human cognition (pp. 131-169). New York, NY: Oxford University Press.

Richardson, J. T. E. (2000). Researching student learning approaches to studying in campus-based and distance education. Buckingham: SRHE \& Open University Press Retrieved from http://www.open. edu/openlearnworks/mod/oucontent/view.php?id=11722.

Richardson, J. T. E. (2007a). Motives, attitudes and approaches to studying in distance education. Higher Education, 54, 385-416. doi:10.1007/s10734-006-9003-y.

Richardson, J. T. E. (2007b). Variations in student learning and perceptions of academic quality. In N. Entwistle, P. Tomlinson, \& J. Dockrell (Eds.), Student learning and university teaching British Journal of Educational Psychology monograph series II no. 4 (pp. 61-71). Leicester: British Psychological Society.

Richardson, J. T. E. (2013). Approaches to studying across the adult life span: evidence from distance education. Learning and Individual Differences, 26, 74-80. doi:10.1016/j.lindif.2013.04.012.

Richardson, J. T. E. (2015a). Approaches to learning or levels of processing: what did Marton and Säljö (1976a) really say? The legacy of the work of the Göteborg group in the 1970s. Interchange, 46, 239-269. doi:10.1007/s10780-015-9251-9.

Richardson, J. T. E. (2015b). The under-attainment of ethnic minority students in UK higher education: what we know and what we don't know. Journal of Further and Higher Education, 39(2), 278-291. doi:10.1080 /0309877X.2013.858680.

Richardson, J. T. E., Dawson, L., Sadlo, G., Jenkins, V., \& McInnes, J. (2007). Perceived academic quality and approaches to studying in the health professions. Medical Teacher, 29, e108-e116. doi:10.1080 /01421590701529389.

Roediger, H. L., Stadler, M. L., Weldon, M. S., \& Riegler, G. L. (1992). Direct comparison of two implicit memory tests: word fragment and word stem completion. Journal of Experimental Psychology: Learning, Memory, and Cognition, 18, 1251-1269. doi:10.1037/0278-7393.18.6.1251.

Sadlo, G., \& Richardson, J. T. E. (2003). Approaches to studying and perceptions of the academic environment in students following problem-based and subject-based curricula. Higher Education Research and Development, 22, 253-274. doi:10.1080/0729436032000145130.

Strobel, J., \& van Barneveld, A. (2009). When is PBL more effective? A meta-synthesis of meta-analyses comparing PBL to conventional classrooms. Interdisciplinary Journal of Problem-Based Learning, 3(1), 44-58. doi:10.7771/1541- 5015.1046.

Watkins, D., \& Hattie, J. (1985). A longitudinal study of the approaches to learning of Australian tertiary students. Human Learning, 4, 127-141. 